Article

\title{
Ten SNPs May Affect Type 2 Diabetes Risk in Interaction with Prenatal Exposure to Chinese Famine
}

\author{
Chao Song $\mathbb{D}^{\mathbb{C}}$, Caicui Ding, Fan Yuan, Ganyu Feng, Yanning Ma and Ailing Liu * \\ National Institute for Nutrition and Health, Chinese Center for Disease Control and Prevention, \\ Beijing 100050, China; songchao@ninh.chinacdc.cn (C.S.); dingcc@ninh.chinacdc.cn (C.D.); \\ yuanfan@ninh.chinacdc.cn (F.Y.); fenggy@ninh.chinacdc.cn (G.F.); mayn@ninh.chinacdc.cn (Y.M.) \\ * Correspondence: liual@ninh.chinacdc.cn; Tel.: +86-10-6623-7059
}

Received: 13 October 2020; Accepted: 14 December 2020; Published: 18 December 2020

check for updates

\begin{abstract}
Increasing studies have demonstrated that gene and famine may interact on type 2 diabetes risk. The data derived from the cross-sectional 2010-2012 China National Nutrition and Health Survey (CNNHS) was examined to explore whether gene and famine interacted to influence type 2 diabetes risk. In total, 2216 subjects were involved. The subjects born in 1960 and 1961 were selected as the famine-exposed group, whereas subjects born in 1963 were selected as the unexposed group. A Mass Array system was used to detect the genotypes of 50 related single-nucleotide polymorphisms (SNPs). Interactions were found between prenatal exposure to famine and ten SNPs (rs10401969, rs10886471, rs10946398, rs1470579, rs2796441, rs340874, rs3794991, rs5015480, rs7961581, and rs9470794) on type 2 diabetes risk after adjustments. The stratified results showed that famine exposure exacerbated the effect of CILP2-rs10401969 to fasting serum insulin (FINS), GRK5-rs10886471 to fasting plasma glucose (FPG) and FINS, IGF2BP2-rs1470579 to FINS, TLE1-rs2796441 to impaired fasting glucose (IFG), PROX1-rs340874 to impaired glucose tolerance (IGT), GATAD2A-rs3794991 to FINS, TSPAN8/LGR5-rs7961581 to FPG, and ZFAND3-rs9470794 to IGT and FINS. Famine exposure weakened the effect of CDKAL1-rs10946398 to type 2 diabetes. Famine exposure weakened the effect of HHEX-rs5015480 to IFG, but exacerbated the effect of HHEX-rs5015480 to FINS. The present study suggests that ten SNPs may affect type 2 diabetes risk in interaction with prenatal exposure to Chinese famine.
\end{abstract}

Keywords: diabetes; famine; interaction; prenatal period

\section{Introduction}

The occurrence of type 2 diabetes is not only influenced by the environment, but also by inherent cause. By associating regions of the genome with disease susceptibility, loci influencing type 2 diabetes risk have been identified [1]. Furthermore, convincing evidence has shown that genetic factors also play an important role in causing type 2 diabetes, and more than 100 loci have been confirmed to be contributable to type 2 diabetes risk in different ethnic populations, which promises to accelerate our understanding of disease pathology [2].

During the period of 1959-1961, Chinese people suffered the most severe famine in the world [3]. Some studies found that exposure to severe famine in the prenatal or postnatal period was associated with the development of type 2 diabetes in adulthood. Data from different periods of famine around the world have been utilized to explore the association of early life malnutrition and type 2 diabetes risk in adulthood, and the "famine effect" has been found in China and some foreign studies, including Asian, European, and African populations [4-11].

The individuals exposed to famine may involve adaptations to malnutrition, with fetal adaptations including reduced growth, small size at birth, or low birth weight [12]. One study assessed the 
interaction between birth weight and genetic susceptibility to type 2 diabetes in two independent prospective cohorts in the USA, and the data suggested that low birth weight and genetic susceptibility to obesity may affect adulthood risk of type 2 diabetes [13]. The latest research has found the existence of interactions between famine and some genes in the occurrence of type 2 diabetes, which means that some variants may influence susceptibility of type 2 diabetes amongst the population experiencing famine or malnutrition in early life, such as SIRT1, PPAR- $\gamma 2$ Pro12Ala, IGF2BP2, etc. [14-16]. The gene-environment interactions resulting from famine and increased type 2 diabetes risk have contributed to the epidemic of type 2 diabetes in China [17]. Thus, we used data from the China National Nutrition and Health Survey (CNNHS) 2010-2012 to explore whether there were some genetic variants which may affect type 2 diabetes risk with prenatal exposure to Chinese famine.

\section{Materials and Methods}

\subsection{Data Resources}

The CNNHS 2010-2012 was a national representative cross-sectional study which assessed the nutrition and health status of Chinese residents. The 2010-2012 survey covered all 31 provinces, autonomous regions, and municipalities throughout China (except for Taiwan, Hong Kong, and Macao). The country was divided into four strata (large cities, medium and small cities, ordinary rural areas, and poor rural areas), according to their characteristics of economy and social development, using the data from the China National Bureau of Statistics [18]. In this survey, subjects were recruited using a stratified multistage cluster and probability proportional to size sampling design, which was described in a previous study [19].

The Chinese famine lasted for three years, in 1959-1961. Therefore, we established our famine cohort: the subjects born in 1960-1961 were selected as the famine-exposed group, whereas subjects born in 1963 were selected as the unexposed group. The subjects in the two groups were 1:1 matched by gender and birth areas, with 1108 subjects in each group. Questionnaires were used to collect information on demographic characteristics. Blood samples were also collected from the subjects. The exclusion criteria were: unqualified blood sample; failure in DNA extraction; abnormal gene detect results; incomplete basic information; subjects suffered from liver/kidney/heart diseases/cancer; subjects had been diagnosed as type 2 diabetes and had changed their lifestyle.

The protocols of the 2010-2012 CNNHS and "Fetal origin hypothesis of diabetes: thrifty genotype hypothesis or thrifty phenotype" were both approved by the Ethical Committee of the National Institute for Nutrition and Health, Chinese Center for Disease Control and Prevention (No. 2013-018, No. 2013-010). Signed consent forms were obtained from all subjects.

\subsection{Assessments of Variables}

Information about demographic characteristics, dietary factors, smoking and drinking status, exercise data and anthropometric data were derived from the questionnaires. Self-reported education levels were classified as illiteracy to primary school, junior middle school, and senior high school or higher. Current economic status was assessed by the per capita annual income of households in 2011, and was divided into three levels: $<20,000,20,000-40,000$ and $>40,000$ RMB. Smoking and drinking status was classified as "yes" or "no".

A validated semi-quantitative food frequency questionnaire and $24 \mathrm{~h}$ recall method for the last three consecutive days (two weekdays and one weekend day) were used to collect data regarding dietary intake. In the present study, we only considered the intake of cereals and beans, and the intake of meat and poultry as confounders, as they have been found to be associated with type 2 diabetes [20,21]. The Chinese Dietary Guideline recommends that the reference intake of meat and poultry is between $40 \mathrm{~g}$ and $75 \mathrm{~g}$, and the reference intake of cereals and beans is between $50 \mathrm{~g}$ and $150 \mathrm{~g}$ [22]. Thus, we assessed the intake according to the reference intake. The intake of meat and poultry was divided into three categories: low ( $<50 \mathrm{~g} / \mathrm{d}$ ), medium (from $\geq 50$ to $\leq 150 \mathrm{~g} / \mathrm{d}$ ), and high 
(>150 g/d). Dietary intake of cereals and beans was divided into three categories: insufficient $(<40 \mathrm{~g} / \mathrm{d})$, sufficient (from $\geq 40$ to $\leq 75 \mathrm{~g} / \mathrm{d}$ ), and excessive $(>75 \mathrm{~g} / \mathrm{d}$ ). Physical activity questionnaires were used to collect physical activity variables, such as whether exercise was taken or not, and total sedentary time (watching TV, using computers, playing video games, and reading) in the subjects' leisure time. BMI was calculated as weight in kilograms divided by height in meters squared $\left(\mathrm{kg} / \mathrm{m}^{2}\right)$.

Fasting glucose was measured by collecting morning fasting venous blood samples. Then, the subjects without known diabetes were required to take $75 \mathrm{~g}$ oral glucose, and after two hours, venous blood samples were collected again to obtain 2-h plasma glucose. We used criteria proposed by the World Health Organization, the International Diabetes Federation, and the American Diabetes Association on diabetes mellitus [23-26]. Impaired fasting glucose (IFG) was defined as fasting plasma glucose $(\mathrm{FPG}) \geq 6.1$ and $<7.0 \mathrm{mmol} / \mathrm{L}, 2$-h plasma glucose $<7.8 \mathrm{mmol} / \mathrm{L}$. Impaired glucose tolerance (IGT) was defined as FPG $<7.0 \mathrm{mmol} / \mathrm{L}$ and 2-h plasma glucose $\geq 7.8$ and $<11.1 \mathrm{mmol} / \mathrm{L}$. Type 2 diabetes was defined as FPG $\geq 7.0 \mathrm{mmol} / \mathrm{L}$ and/or $2-\mathrm{h}$ plasma glucose $\geq 11.0 \mathrm{mmol} / \mathrm{L}$ and/or a previous clinical diagnosis of type 2 diabetes. Fasting serum insulin (FINS) was measured by an Iodine [ $\left.{ }^{125} \mathrm{I}\right]$ Insulin Radioimmunoassay Kit.

\subsection{Genotyping}

According to the latest reports in the genome-wide association study and other studies, 61 related single-nucleotide polymorphisms (SNPs) were included in our study [27-33]. A Mass Array system (Agena, San Diego, USA) was used to detect the genotypes of 61 SNPs. No significant departures were detected from the Hardy-Weinberg equilibrium (HWE) among subjects without type 2 diabetes by using the chi-square test, which suggested the sample was representative (Supplementary Table S1). At the individual level, we removed the samples whose call rates were less than $50 \%$. At the SNP level, we excluded the SNPs if their call rate was $<80 \%$ and/or their $p$-value for HWE was $<0.0001$ in subjects without type 2 diabetes. Thus, 2216 subjects and 50 SNPs were ultimately included in the analysis.

\subsection{Statistical Analysis}

The statistical software package SAS version 9.4 (SAS Institute, Cary, NC, USA) was used for data analysis. A $p$-value $<0.05$ was considered significant. Continuous variables were presented as mean \pm SD or median (P25, P75) according to their distribution, and categorical variables were presented as frequency and percentage. Chi-square and $t$-tests were used for the comparison of differences between the exposed and unexposed groups. Interactions were tested by creating interaction terms for each genetic variant (coded 0, 1 for not carrying and carrying the risk allele respectively) with the exposed group (coded 0 and 1 for unexposed and exposed subjects, respectively). We tested the multiplicative interaction with famine exposure by using a likelihood ratio test comparing models with and without the cross-product term. Then, associations between SNPs and type 2 diabetes risk were performed according to fetal exposure to famine. General linear model regression was used to test the relationship between FPG, FINS, and SNPs, adjusting for covariates such as age, gender, education level, economic status, smoking, drinking, the intake of meat and poultry, the intake of cereals and beans, physical exercise, sedentary time, BMI, and family history of type 2 diabetes. Logistic regression was used to estimate the ORs for the risk of type 2 diabetes, IFG, and IGT after adjusting for the aforementioned covariates.

\section{Results}

A total of 2216 subjects were included in the current study, with an average age of 49.7 years. General characteristics of subjects between exposed and unexposed groups are shown in Table 1. There were group differences in age, education level and drinking.

Table 2 shows the interactions between genetic variants and prenatal exposure to famine as they influence type 2 diabetes risk. Interactions were found between prenatal exposure to famine and ten SNPs (rs10401969, rs10886471, rs10946398, rs1470579, rs2796441, rs340874, rs3794991, rs5015480, 
rs7961581 and rs9470794) and type 2 diabetes risk after adjustments for age, gender, education level, economic status, smoking, drinking, the intake of meat and poultry, the intake of cereals and beans, physical exercise, sedentary time, BMI, and family history of type 2 diabetes $(p<0.05)$.

Table 1. Basic information of subjects.

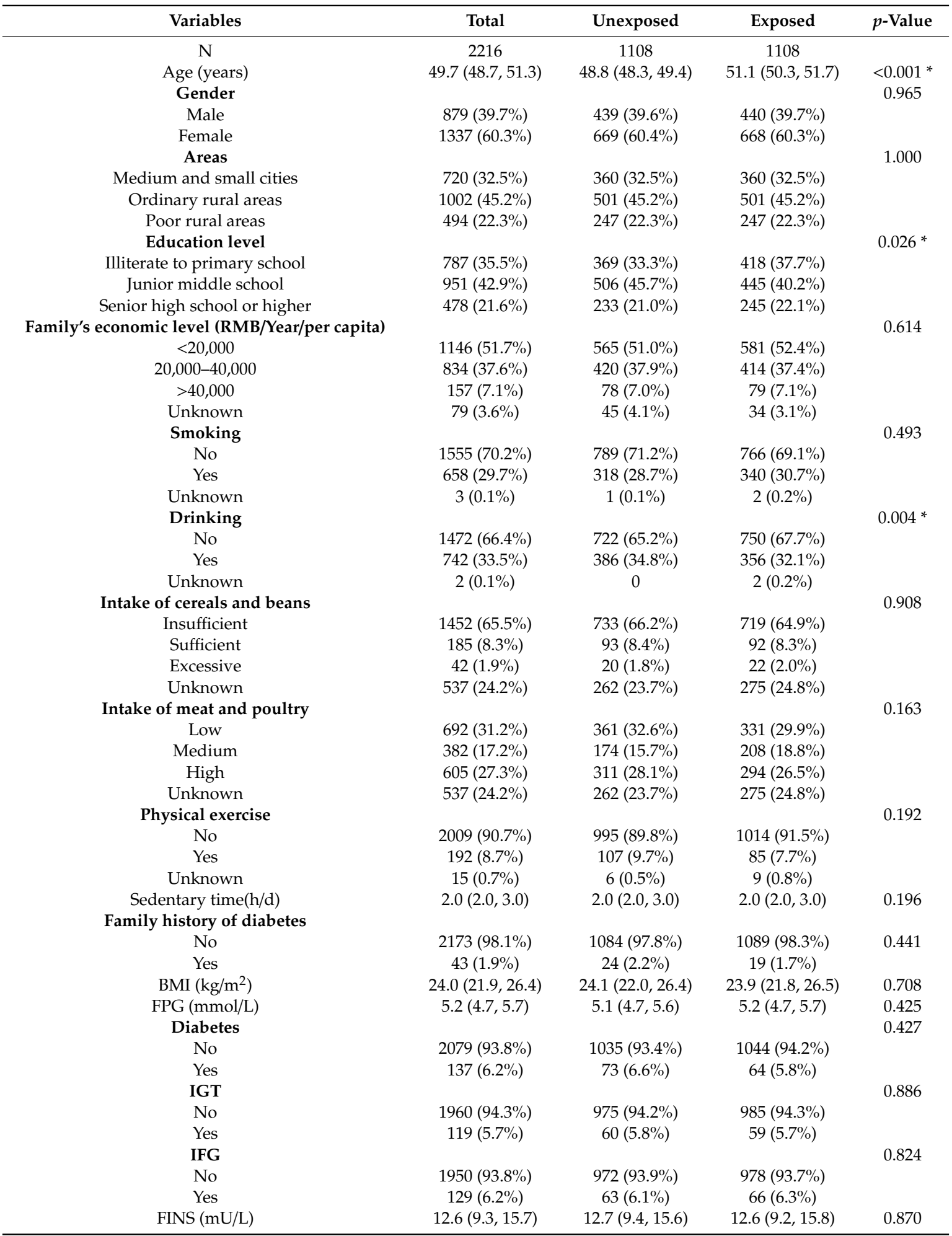


Table 2. Interactions of single-nucleotide polymorphisms (SNPs) with prenatal exposure to famine.

\begin{tabular}{|c|c|c|c|c|c|c|}
\hline SNP & Loci & Diabetes & IGT & IFG & FPG & FINS \\
\hline rs10401969 & CILP2 & 0.145 & 0.763 & 0.545 & 0.094 & 0.046 * \\
\hline rs10830963 & MTNR1B & 0.314 & 0.565 & 0.347 & 0.393 & 0.906 \\
\hline rs10842994 & KLHDC5 & 0.903 & 0.701 & 0.888 & 0.736 & 0.916 \\
\hline rs10886471 & GRK5 & 0.900 & 0.872 & 0.659 & 0.258 & $0.005^{*}$ \\
\hline rs10906115 & CDC123, CAMK1D & 0.969 & 0.187 & 0.164 & 0.514 & 0.748 \\
\hline rs10946398 & CDKAL1 & $0.005 *$ & 0.442 & 0.935 & 0.238 & 0.400 \\
\hline rs11257655 & CDC123 & 0.657 & 0.398 & 0.243 & 0.705 & 0.766 \\
\hline rs11634397 & ZFAND6 & 0.337 & 0.987 & 0.936 & 0.399 & 0.513 \\
\hline rs12454712 & BCL2 & 0.365 & 0.152 & 0.136 & 0.540 & 0.614 \\
\hline rs12970134 & MC4R & 0.549 & 0.211 & 0.286 & 0.248 & 0.416 \\
\hline rs13266634 & SLC30A8 & 0.695 & 0.439 & 0.284 & 0.805 & 0.860 \\
\hline rs1470579 & IGF2BP2 & 0.612 & 0.829 & 0.142 & 0.635 & $0.022 *$ \\
\hline rs1535500 & KCNK16 & 0.482 & 0.347 & 0.491 & 0.553 & 0.795 \\
\hline rs1552224 & CENTD2 & 0.951 & 0.959 & 0.954 & 0.648 & 0.873 \\
\hline rs1558902 & FTO & 0.119 & 0.091 & 0.291 & 0.254 & 0.700 \\
\hline rs16861329 & ST6GAL1 & 0.643 & 0.064 & 0.112 & 0.382 & 0.553 \\
\hline rs17584499 & PTPRD & 0.432 & 0.508 & 0.453 & 0.351 & 0.775 \\
\hline rs2028299 & AP3S2 & 0.948 & 0.574 & 0.452 & 0.843 & 0.820 \\
\hline rs2191349 & DGKB, TMEM195 & 0.284 & 0.579 & 0.139 & 0.860 & 0.319 \\
\hline rs243021 & BCL11A & 0.611 & 0.403 & 0.090 & 0.296 & 0.342 \\
\hline rs2796441 & TLE1 & 0.412 & 0.172 & $0.039 *$ & 0.709 & 0.322 \\
\hline rs2943641 & IRS1 & 0.999 & 0.952 & 0.949 & 0.881 & 0.360 \\
\hline rs340874 & PROX1 & 0.830 & 0.024 * & 0.527 & 0.687 & 0.958 \\
\hline rs3794991 & GATAD2A & 0.720 & 0.353 & 0.456 & 0.966 & $0.018^{*}$ \\
\hline rs3923113 & GRB14 & 0.903 & 0.888 & 0.160 & 0.399 & 0.059 \\
\hline rs4430796 & HNF1B & 0.565 & 0.516 & 0.787 & 0.512 & 0.341 \\
\hline rs459193 & ANKRD55 & 0.627 & 0.867 & 0.925 & 0.976 & 0.099 \\
\hline rs4607103 & ADAMTS9 & 0.583 & 0.714 & 0.187 & 0.426 & 0.338 \\
\hline rs4607517 & GCK & 0.719 & 0.116 & 0.567 & 0.461 & 0.056 \\
\hline rs4858889 & SCAP & 0.383 & 0.980 & 0.824 & 0.765 & 0.845 \\
\hline rs5015480 & HHEX & 0.785 & 0.377 & $0.036 *$ & 0.428 & 0.346 \\
\hline rs516946 & ANK1 & 0.804 & 0.927 & 0.474 & 0.793 & 0.700 \\
\hline rs5215 & KCNJ11 & 0.943 & 0.477 & 0.192 & 0.564 & 0.567 \\
\hline rs6815464 & MAEA & 0.820 & 0.194 & 0.081 & 0.286 & 0.395 \\
\hline rs7041847 & GLIS3 & 0.265 & 0.193 & 0.088 & 0.053 & 0.299 \\
\hline rs7172432 & $\mathrm{C} 2 \mathrm{CD} 4 \mathrm{~A}, \mathrm{C} 2 \mathrm{CD} 4 \mathrm{~B}$ & 0.133 & 0.344 & 0.381 & 0.522 & 0.588 \\
\hline rs7178572 & HMG20A & 0.108 & 0.946 & 0.998 & 0.711 & 0.274 \\
\hline rs7202877 & BCAR1 & 0.917 & 0.881 & 0.852 & 0.762 & 0.817 \\
\hline rs7403531 & RASGRP1 & 0.572 & 0.080 & 0.802 & 0.489 & 0.184 \\
\hline rs7593730 & RBMS1, ITGB6 & 0.884 & 0.261 & 0.315 & 0.528 & 0.958 \\
\hline rs7612463 & UBE2E2 & 0.967 & 0.882 & 0.146 & 0.176 & 0.291 \\
\hline rs780094 & GCKR & 0.566 & 0.869 & 0.277 & 0.589 & 0.178 \\
\hline rs7961581 & TSPAN8, LGR5 & 0.073 & 0.642 & 0.163 & 0.017 * & 0.944 \\
\hline rs8050136 & FTO & 0.102 & 0.458 & 0.360 & 0.282 & 0.867 \\
\hline rs8090011 & LAMA1 & 0.114 & 0.679 & 0.499 & 0.177 & 0.851 \\
\hline rs831571 & PSMD6 & 0.569 & 0.402 & 0.815 & 0.659 & 0.144 \\
\hline rs864745 & JAZF1 & 0.453 & 0.283 & 0.800 & 0.188 & 0.939 \\
\hline rs896854 & TP53INP1 & 0.184 & 0.747 & 0.452 & 0.280 & 0.191 \\
\hline rs9470794 & ZFAND3 & 0.946 & 0.146 & 0.053 & 0.356 & $0.007^{*}$ \\
\hline rs972283 & KLF14 & 0.704 & 0.616 & 0.162 & 0.837 & 0.155 \\
\hline
\end{tabular}


Table 3 showed that FPG increased by $0.474 \mathrm{mmol} / \mathrm{L}$ among risk allele carriers (rs10886471) in the exposed group $(p=0.032)$, and FINS decreased by $2.996 \mathrm{mU} / \mathrm{L}$ among risk allele carriers in the unexposed subjects $(p=0.023)$. There was a significant association for rs10946398 with type 2 diabetes for risk allele carriers in the unexposed group (OR $=3.263,95 \% \mathrm{CI}: 1.584-6.724, p=0.001$ ). FINS increased by $1.427 \mathrm{mU} / \mathrm{L}$ among risk allele carriers (rs1470579) in the exposed subjects ( $p=0.011$ ). FINS increased by $1.725 \mathrm{mU} / \mathrm{L}$ among risk allele carriers (rs3794991) in the exposed group ( $p=0.046$ ). There was a significant association for rs5015480 with IFG (OR $=1.941,95 \%$ CI: 1.119-3.366, $p=0.018$ ) for risk allele carriers in the unexposed group, and FINS increased by $1.260 \mathrm{mU} / \mathrm{L}$ among risk allele carriers in the exposed group $(p=0.032)$. FPG increased by $0.171 \mathrm{mmol} / \mathrm{L}$ among risk allele carriers (rs7961581) in the exposed subjects $(p=0.042)$. There was a significant association of rs9470794 with IGT for risk allele carriers in the exposed group (OR $=7.902,95 \%$ CI: $1.063-58.735, p=0.043$ ), and FINS increased by $2.105 \mathrm{mU} / \mathrm{L}$ among risk allele carriers in the exposed group $(p=0.018)$. In the exposed subjects, the risk allele carriers (rs10401969) tended to increase with FINS $(p=0.092)$, whereas this was not true in the unexposed subjects $(p=0.210)$. There was a borderline significant association between rs 2796441 and IFG (OR $=0.587,95 \%$ CI: 0.336-1.026), $p=0.061)$, as well as rs340874 and IGT $(\mathrm{OR}=0.616,95 \% \mathrm{CI}: 0.352-1.077, p=0.089)$ in the unexposed subjects. 
Table 3. Associations between SNPs and diabetes risk according to prenatal exposure to famine.

\begin{tabular}{|c|c|c|c|c|c|c|c|c|c|c|c|c|}
\hline \multirow{2}{*}{ SNP } & \multirow{2}{*}{ Group } & \multirow{2}{*}{ Risk Allele } & Diabetes & \multirow{2}{*}{$p$-Value } & IGT & \multirow{2}{*}{$p$-Value } & IFG & \multirow{2}{*}{$p$-Value } & FPG & \multirow{2}{*}{$p$ Value } & FINS & \multirow{2}{*}{$p$-Value } \\
\hline & & & OR $(95 \% \mathrm{CI})$ & & OR $(95 \% \mathrm{CI})$ & & OR $(95 \% \mathrm{CI})$ & & $\beta$ & & $\beta$ & \\
\hline \multirow[t]{4}{*}{ rs10401969 } & unexposed & 0 & 1.00 (Ref) & & 1.00 (Ref) & & 1.00 (Ref) & & 1.00 (Ref) & & 1.00 (Ref) & \\
\hline & unexposed & 1 & $1.007(0.496,2.045)$ & 0.985 & $1.070(0.522,2.196)$ & 0.853 & $1.592(0.807,3.140)$ & 0.180 & $0.123(-0.062,0.309)$ & 0.193 & $-0.959(-2.459,0.541)$ & 0.210 \\
\hline & exposed & 0 & 1.00 (Ref) & & 1.00 (Ref) & & 1.00 (Ref) & & 1.00 (Ref) & & 1.00 (Ref) & \\
\hline & exposed & 1 & $0.502(0.193,1.306)$ & 0.158 & $0.978(0.456,2.099)$ & 0.955 & $1.048(0.524,2.095)$ & 0.895 & $-0.106(-0.325,0.113)$ & 0.345 & $1.314(-0.214,2.842)$ & 0.092 \\
\hline \multirow[t]{4}{*}{ rs10886471 } & unexposed & 0 & 1.00 (Ref) & & 1.00 (Ref) & & 1.00 (Ref) & & 1.00 (Ref) & & 1.00 (Ref) & \\
\hline & unexposed & 1 & $1.677(0.373,7.538)$ & 0.500 & $t$ & & $1.605(0.370,6.965)$ & 0.527 & $0.201(-0.124,0.526)$ & 0.225 & $-2.996(-5.568,-0.424)$ & $0.023 *$ \\
\hline & exposed & 0 & 1.00 (Ref) & & 1.00 (Ref) & & 1.00 (Ref) & & 1.00 (Ref) & & 1.00 (Ref) & \\
\hline & exposed & 1 & $1.361(0.300,6.178)$ & 0.689 & $1.623(0.210,12.547)$ & 0.643 & $2.754(0.356,21.301)$ & 0.332 & $0.474(0.040,0.907)$ & $0.032 *$ & $2.498(-0.112,5.109)$ & 0.061 \\
\hline \multirow{4}{*}{ rs10946398 } & unexposed & 0 & 1.00 (Ref) & & 1.00 (Ref) & & 1.00 (Ref) & & 1.00 (Ref) & & 1.00 (Ref) & \\
\hline & unexposed & 1 & $3.263(1.584,6.724)$ & 0.001 * & $1.163(0.654,2.067)$ & 0.608 & $1.157(0.650,2.058)$ & 0.621 & $0.085(-0.059,0.228)$ & 0.247 & $0.025(-1.134,1.184)$ & 0.966 \\
\hline & exposed & 0 & 1.00 (Ref) & & $1.00($ Ref) & & 1.00 (Ref) & & 1.00 (Ref) & & 1.00 (Ref) & \\
\hline & exposed & 1 & $0.830(0.466,1.478)$ & 0.526 & $0.867(0.481,1.565)$ & 0.636 & $1.167(0.642,2.122)$ & 0.613 & $-0.050(-0.223,0.124)$ & 0.574 & $-0.663(-1.841,0.515)$ & 0.270 \\
\hline \multirow[t]{4}{*}{ rs1470579 } & unexposed & 0 & 1.00 (Ref) & & $1.00($ Ref) & & 1.00 (Ref) & & $1.00($ Ref) & & 1.00 (Ref) & \\
\hline & unexposed & 1 & $1.373(0.798,2.363)$ & 0.253 & $1.062(0.619,1.821)$ & 0.827 & $1.236(0.719,2.127)$ & 0.443 & $0.039(-0.098,0.175)$ & 0.578 & $-0.400(-1.519,0.720)$ & 0.483 \\
\hline & exposed & 0 & 1.00 (Ref) & & 1.00 (Ref) & & 1.00 (Ref) & & 1.00 (Ref) & & 1.00 (Ref) & \\
\hline & exposed & 1 & $0.990(0.571,1.715)$ & 0.970 & $1.157(0.659,2.030)$ & 0.611 & $0.703(0.404,1.225)$ & 0.214 & $-0.024(-0.186,0.139)$ & 0.774 & $1.427(0.335,2.518)$ & $0.011 *$ \\
\hline \multirow[t]{4}{*}{ rs2796441 } & unexposed & 0 & 1.00 (Ref) & & 1.00 (Ref) & & 1.00 (Ref) & & 1.00 (Ref) & & 1.00 (Ref) & \\
\hline & unexposed & 1 & $1.055(0.599,1.856)$ & 0.854 & $1.346(0.733,2.473)$ & 0.338 & $0.587(0.336,1.026)$ & 0.061 & $-0.000(-0.146,0.145)$ & 0.997 & $0.058(-1.118,1.234)$ & 0.923 \\
\hline & exposed & 0 & 1.00 (Ref) & & 1.00 (Ref) & & 1.00 (Ref) & & 1.00 (Ref) & & 1.00 (Ref) & \\
\hline & exposed & 1 & $0.740(0.423,1.295)$ & 0.292 & $0.790(0.444,1.404)$ & 0.421 & $1.376(0.769,2.460)$ & 0.282 & $-0.025(-0.195,0.146)$ & 0.778 & $-0.779(-1.896,0.339)$ & 0.172 \\
\hline \multirow[t]{4}{*}{ rs340874 } & unexposed & 0 & 1.00 (Ref) & & 1.00 (Ref) & & 1.00 (Ref) & & 1.00 (Ref) & & 1.00 (Ref) & \\
\hline & unexposed & 1 & $0.989(0.567,1.726)$ & 0.969 & $0.616(0.352,1.077)$ & 0.089 & $0.900(0.511,1.586)$ & 0.716 & $-0.036(-0.182,0.111)$ & 0.634 & $-0.318(-1.500,0.863)$ & 0.597 \\
\hline & exposed & 0 & $1.00(\mathrm{Ref})$ & & 1.00 (Ref) & & 1.00 (Ref) & & $1.00(\mathrm{Ref})$ & & 1.00 (Ref) & \\
\hline & exposed & 1 & $0.812(0.459,1.434)$ & 0.472 & $1.472(0.799,2.713)$ & 0.215 & $0.696(0.407,1.190)$ & 0.185 & $0.019(-0.149,0.188)$ & 0.822 & $-0.269(-1.284,0.747)$ & 0.604 \\
\hline \multirow[t]{4}{*}{ rs3794991 } & unexposed & 0 & 1.00 (Ref) & & 1.00 (Ref) & & 1.00 (Ref) & & 1.00 (Ref) & & 1.00 (Ref) & \\
\hline & unexposed & 1 & $0.606(0.245,1.499)$ & 0.278 & $0.532(0.187,1.516)$ & 0.237 & $0.909(0.374,2.208)$ & 0.833 & $0.002(-0.215,0.219)$ & 0.988 & $-1.378(-3.168,0.412)$ & 0.131 \\
\hline & exposed & 0 & 1.00 (Ref) & & 1.00 (Ref) & & 1.00 (Ref) & & 1.00 (Ref) & & 1.00 (Ref) & \\
\hline & exposed & 1 & $1.039(0.424,2.546)$ & 0.934 & $0.973(0.395,2.397)$ & 0.953 & $0.524(0.184,1.497)$ & 0.228 & $0.033(-0.224,0.290)$ & 0.803 & $1.725(0.035,3.416)$ & $0.046 *$ \\
\hline \multirow{4}{*}{ rs5015480 } & unexposed & 0 & 1.00 (Ref) & & 1.00 (Ref) & & 1.00 (Ref) & & 1.00 (Ref) & & 1.00 (Ref) & \\
\hline & unexposed & 1 & $0.995(0.551,1.798)$ & 0.988 & $1.030(0.575,1.844)$ & 0.921 & $1.941(1.119,3.366)$ & $0.018^{*}$ & $0.045(-0.099,0.189)$ & 0.540 & $0.369(-0.803,1.542)$ & 0.536 \\
\hline & exposed & 0 & 1.00 (Ref) & & 1.00 (Ref) & & 1.00 (Ref) & & 1.00 (Ref) & & 1.00 (Ref) & \\
\hline & exposed & 1 & $1.236(0.699,2.183)$ & 0.466 & $0.665(0.351,1.262)$ & 0.212 & $0.839(0.460,1.529)$ & 0.566 & $-0.029(-0.203,0.144)$ & 0.740 & $1.260(0.108,2.412)$ & $0.032 *$ \\
\hline \multirow[t]{4}{*}{ rs7961581 } & unexposed & 0 & 1.00 (Ref) & & 1.00 (Ref) & & 1.00 (Ref) & & 1.00 (Ref) & & 1.00 (Ref) & \\
\hline & unexposed & 1 & $0.625(0.349,1.119)$ & 0.114 & $0.710(0.405,1.247)$ & 0.234 & $0.940(0.539,1.638)$ & 0.826 & $-0.075(-0.213,0.062)$ & 0.282 & $-0.525(-1.607,0.556)$ & 0.341 \\
\hline & exposed & 0 & 1.00 (Ref) & & 1.00 (Ref) & & 1.00 (Ref) & & 1.00 (Ref) & & 1.00 (Ref) & \\
\hline & exposed & 1 & $1.219(0.697,2.132)$ & 0.487 & $0.583(0.312,1.089)$ & 0.090 & $1.629(0.949,2.797)$ & 0.077 & $0.171(0.006,0.335)$ & $0.042 *$ & $-0.463(-1.580,0.654)$ & 0.416 \\
\hline \multirow[t]{4}{*}{ rs9470794 } & unexposed & 0 & 1.00 (Ref) & & 1.00 (Ref) & & 1.00 (Ref) & & 1.00 (Ref) & & 1.00 (Ref) & \\
\hline & unexposed & 1 & $1.518(0.545,4.229)$ & 0.425 & $1.393(0.488,3.977)$ & 0.536 & $0.514(0.239,1.108)$ & 0.090 & $0.086(-0.148,0.319)$ & 0.472 & $-1.468(-3.287,0.351)$ & 0.114 \\
\hline & exposed & 0 & 1.00 (Ref) & & 1.00 (Ref) & & 1.00 (Ref) & & 1.00 (Ref) & & 1.00 (Ref) & \\
\hline & exposed & 1 & $1.417(0.540,3.715)$ & 0.479 & $7.902(1.063,58.735)$ & $0.043 *$ & $1.709(0.598,4.883)$ & 0.317 & $0.235(-0.020,0.490)$ & 0.071 & $2.105(0.363,3.848)$ & 0.018 * \\
\hline
\end{tabular}

${ }^{*} p<0.05$; +: No result due to complete separate data. 


\section{Discussion}

The present study indicates that CILP2-rs10401969, GRK5-rs10886471, CDKAL1-rs10946398, IGF2BP2-rs1470579, TLE1-rs2796441, PROX1-rs340874, GATAD2A-rs3794991, HHEX-rs5015480, TSPAN8/LGR5-rs7961581, and ZFAND3-rs9470794 showed nominally significant interactions with prenatal exposure to famine in type 2 diabetes risk.

The Chinese famine provides a unique opportunity to investigate the interactions of prenatal exposure to famine with type 2 diabetes and related measurements. The latest studies have found that prenatal exposure to famine interacted with some genes in influencing type 2 diabetes [14-16]. Thus, we investigated interactions of SNPs associated with type 2 diabetes in the Chinese population exposed to famine in utero. Our stratified results showed that famine exposure exacerbated the effect of CILP2-rs10401969 to FINS, GRK5-rs10886471 to FPG and FINS, IGF2BP2-rs1470579 to FINS, TLE1-rs2796441 to IFG, PROX1-rs340874 to IGT, GATAD2A-rs3794991 to FINS, TSPAN8/LGR5-rs7961581 to FPG, and ZFAND3-rs9470794 to IGT and FINS. Famine exposure weakened the effect of CDKAL1-rs10946398 to type 2 diabetes. Famine exposure weakened the effect of HHEX-rs5015480 to IFG, but exacerbated the effect of HHEX-rs5015480 to FINS. To our knowledge, the ten SNPs are the first found to interact with prenatal exposure to famine in type 2 diabetes risk.

The IGF2BP2 gene, which encodes the IGF2 mRNA binding protein2, is suggested to play a role in the regulation of insulin production and beta cell function, and IGF2BP2-rs4402960 showed an interaction with prenatal exposure to famine on glucose levels in the Dutch Famine Birth Cohort Study in Amsterdam [15]. Some studies explored the interaction of genes and fetal malnutrition or birth size/weight in type 2 diabetes risk (K121Q, HHEX, CDKN2A/2B, etc.) [12,34]. However, IGF2BP2-rs4402960 did not show an interaction between birth weight and the risk of developing type 2 diabetes in the Helsinki Birth Cohort Study [34]. Variants in CDKAL1 were associated with beta cell function and influenced insulin secretion. The Helsinki Birth Cohort Study investigated the interaction between birth weight and CDKAL1-rs7754840 on the risk of developing type 2 diabetes, and the results were negative [34]. CDKAL1-rs10946398 was previously reported to be associated with birth weight and type 2 diabetes [35], so it was possible that CDKAL1-rs10946398 influenced type 2 diabetes risk by affecting birth weight, or CDKAL1-rs10946398 indeed had an interaction with prenatal exposure to famine in type 2 diabetes risk, but such explanations are speculative and they still need to be replicated in different cohorts. HHEX was associated with impaired insulin release by influencing beta cell development, and HHEX-rs1111875 was found to have an interaction with low birth weight in type 2 diabetes in the Helsinki Birth Cohort Study, which indicated that low birth weight might affect the strength of the association of the variants with type 2 diabetes [34,36].

CILP2 encodes cartilage intermediate layer protein 2, GRK5 plays a crucial role in multiple G-protein-coupled receptors(GPCRs) and non-GPCR substrates which are either key regulators of glucose homeostasis or inflammation, TLE1 and GATAD2A are protein-coding genes, PROX1 influences insulin secretion by influencing beta cell development, TSPAN8/LGR5 seems to result in pancreatic beta cell dysfunction and influences insulin secretion, and the expression of ZFAND3 was found in mouse pancreatic islets with altered beta-cell function $[2,29,31,36]$. Previous researchers found that exposure to famine in utero or food restriction during gestation impaired and reduced glucose tolerance or decreased beta cell mass [16], which predisposed humans to type 2 diabetes in later life [37,38]. Most of these type 2 diabetes susceptibility genes were associated with the expression and/or function in beta cells and changed insulin secretion. Whether these SNPs involved in fetal development can influence type 2 diabetes in adulthood still needs to be replicated in later cohorts.

The present study has several advantages. It was the first time the interaction of so many SNPs and fetal exposure to Chinese famine in type 2 diabetes risk was examined. Moreover, our study utilized national representative data and provided a scenario to assess whether the variants influence the established association between prenatal exposure to famine and type 2 diabetes risk. We found several variants that showed interactions, although these variants still need to be confirmed in later studies. There were also some limitations which should be mentioned. Although we considered some 
lifestyle factors, other confounding factors such as the consumption of sugar-sweetened beverages, eggs, and fruits and vegetables were not considered in our study. Additionally, the mechanism of how these SNPs interact with prenatal famine on type 2 diabetes risk still remains unclear, and should be examined in the future.

\section{Conclusions}

Our study suggests that ten SNPs may be genetic factors influencing type 2 diabetes risk among famine-exposed subjects, which might synergistically impair the development and function of beta cells, increasing type 2 diabetes risk in adulthood.

Supplementary Materials: The following are available online at http://www.mdpi.com/2072-6643/12/12/3880/s1, Table S1: Hardy-Weinberg equilibrium test.

Author Contributions: The authors' contributions were as follows: C.S. conceived the study, collected and analyzed the data, wrote and revised the manuscript; C.D., F.Y., G.F., and Y.M. collected the data; A.L. supervised the study and contributed to the discussion, interpretation of the data, and manuscript revision. All authors have read and agreed to the published version of the manuscript.

Funding: This research was funded by the National Natural Science Foundation of China (No. 81372990).

Acknowledgments: The authors thank all team members in this project.

Conflicts of Interest: The authors declare no conflict of interest.

\section{References}

1. Grotz, A.K.; Gloyn, A.L.; Thomsen, S.K. Prioritising causal genes at type 2 diabetes risk loci. Curr. Diabetes Rep. 2017, 17, 76. [CrossRef]

2. Ndiaye, F.K.; Ortalli, A.; Canouil, M.; Huyvaert, M.; Salazar-Cardozo, C.; Lecoeur, C.; Verbanck, M.; Pawlowski, V.; Boutry, R.; Durand, E.; et al. Expression and functional assessment of candidate type 2 diabetes susceptibility genes identify four new genes contributing to human insulin secretion. Mol. Metab. 2017, 6, 459-470. [CrossRef]

3. Yang, D.T. China's agricultural crisis and famine of 1959-1961: A survey and comparison to soviet famines. Comp. Econ. Stud. 2008, 50, 1-29. [CrossRef]

4. Wang, N.; Cheng, J.; Han, B.; Li, Q.; Chen, Y.; Xia, F.; Jiang, B.; Jensen, M.D.; Lu, Y. Exposure to severe famine in the prenatal or postnatal period and the development of diabetes in adulthood: An observational study. Diabetologia 2017, 60, 262-269. [CrossRef] [PubMed]

5. Wang, J.; Li, Y.; Han, X.; Liu, B.; Hu, H.; Wang, F.; Li, X.; Yang, K.; Yuan, J.; Yao, P.; et al. Exposure to the chinese famine in childhood increases type 2 diabetes risk in adults. J. Nutr. 2016, 146, 2289-2295. [CrossRef] [PubMed]

6. Li, C.; Lumey, L.H. Exposure to the chinese famine of 1959-61 in early life and long-term health conditions: A systematic review and meta-analysis. Int. J. Epidemiol. 2017, 46, 1157-1170. [CrossRef] [PubMed]

7. Xu, H.; Li, L.; Zhang, Z.; Liu, J. Is natural experiment a cure? Re-examining the long-term health effects of china's 1959-1961 famine. Soc. Sci. Med. 2016, 148, 110-122. [CrossRef]

8. Li, J.; Liu, S.; Li, S.; Feng, R.; Na, L.; Chu, X.; Wu, X.; Niu, Y.; Sun, Z.; Han, T.; et al. Prenatal exposure to famine and the development of hyperglycemia and type 2 diabetes in adulthood across consecutive generations: A population-based cohort study of families in suihua, china. Am. J. Clin. Nutr. 2017, 105, 221-227. [CrossRef]

9. Liu, L.; Wang, W.; Sun, J.; Pang, Z. Association of famine exposure during early life with the risk of type 2 diabetes in adulthood: A meta-analysis. Eur. J. Nutr. 2016, 57, 741-749. [CrossRef]

10. Van Abeelen, A.F.; Elias, S.G.; Bossuyt, P.M.; Grobbee, D.E.; van der Schouw, Y.T.; Roseboom, T.J.; Uiterwaal, C.S. Famine exposure in the young and the risk of type 2 diabetes in adulthood. Diabetes 2012, 61, 2255-2260. [CrossRef]

11. Wang, Z.; Zou, Z.; Yang, Z.; Dong, Y.; Song, J.; Dong, B.; Ma, J.; Arnold, L. The association between fetal-stage exposure to the china famine and risk of diabetes mellitus in adulthood: Results from the china health and retirement longitudinal study. BMC Public Health 2018, 18, 1205. [CrossRef] [PubMed] 
12. Kubaszek, A.; Markkanen, A.; Eriksson, J.G.; Forsen, T.; Osmond, C.; Barker, D.J.; Laakso, M. The association of the $\mathrm{k} 121 \mathrm{q}$ polymorphism of the plasma cell glycoprotein-1 gene with type 2 diabetes and hypertension depends on size at birth. J. Clin. Endocrinol. Metab. 2004, 89, 2044-2047. [CrossRef] [PubMed]

13. Li, Y.; Qi, Q.; Workalemahu, T.; Hu, F.B.; Qi, L. Birth weight, genetic susceptibility, and adulthood risk of type 2 diabetes. Diabetes Care 2012, 35, 2479-2484. [CrossRef] [PubMed]

14. de Rooij, S.R.; Painter, R.C.; Phillips, D.I.W.; Osmond, C.; Tanck, M.W.T.; Defesche, J.C.; Bossuyt, P.M.M.; Michels, R.P.J.; Bleker, O.P.; Roseboom, T.J. The effects of the pro12ala polymorphism of the peroxisome proliferator-activated receptor- $\gamma 2$ gene on glucose/insulin metabolism interact with prenatal exposure to famine. Diabetes Care 2006, 29, 1052-1057. [CrossRef] [PubMed]

15. Van Hoek, M.; Langendonk, J.G.; de Rooij, S.R.; Sijbrands, E.J.; Roseboom, T.J. Genetic variant in the igf2bp2 gene may interact with fetal malnutrition to affect glucose metabolism. Diabetes 2009, 58, 1440-1444. [CrossRef]

16. Botden, I.P.; Zillikens, M.C.; de Rooij, S.R.; Langendonk, J.G.; Danser, A.H.; Sijbrands, E.J.; Roseboom, T.J. Variants in the sirt1 gene may affect diabetes risk in interaction with prenatal exposure to famine. Diabetes Care 2012, 35, 424-426. [CrossRef]

17. Zimmet, P.; Shi, Z.; El-Osta, A.; Ji, L. Epidemic t2dm, early development and epigenetics: Implications of the chinese famine. Nat. Rev. Endocrinol. 2018, 14, 738-746. [CrossRef]

18. Zhao, L.; Ma, G.; Piao, J.; Zhang, J.; Yu, D.; He, Y.; Huo, J.; Hu, X.; Yang, Z.; Yang, X. Scheme of the 2010-2012 chinese nutrition and health surveillance. Zhonghua Yu Fang Yi Xue Za Zhi Chin. J. Prev. Med. 2016, 50, 204-207.

19. Hu, Y.; Chen, J.; Wang, R.; Li, M.; Yun, C.; Li, W.; Yang, Y.; Piao, J.; Yang, X.; Yang, L. Vitamin d nutritional status and its related factors for chinese children and adolescents in 2010-2012. Nutrients 2017, 9, 1024. [CrossRef]

20. Venn, B.J.; Mann, J.I. Cereal grains, legumes and diabetes. Eur. J. Clin. Nutr. 2004, 58, 1443-1461. [CrossRef]

21. Shan, R.; Duan, W.; Liu, L.; Qi, J.; Gao, J.; Zhang, Y.; Du, S.; Han, T.; Pang, X.; Sun, C.; et al. Low-carbohydrate, high-protein, high-fat diets rich in livestock, poultry and their products predict impending risk of type 2 diabetes in chinese individuals that exceed their calculated caloric requirement. Nutrients 2018, 10, 77. [CrossRef] [PubMed]

22. Society, C.N. Chinese Dietary Guideline; People's Medical Publishing House: Beijing, China, 2016.

23. WHO/IDF. Definition and Diagnosis of Diabetes Mellitus and Intermediate Hyperglycemia. Available online: https://www.who.int/publications/i?healthtopics=17f23e6d-2c9a-4f9e-9a08-0151693e0d0a\& publishingoffices-hidden=true (accessed on 3 December 2020).

24. WHO(1999). Definition, Diagnosis and Classification of Diabetes Mellitus and Its Complications: Report of a WHO Consultation. Part 1, Diagnosis and Classification of Diabetes Mellitus. World Health Organization. Available online: https://apps.who.int/iris/handle/10665/66040 (accessed on 17 December 2020).

25. WHO. Diagnosis and Management of Type 2 Diabetes. Available online: https:/www.who.int/health-topics/ diabetes\#tab=tab_1 (accessed on 3 December 2020).

26. American Diabetes Association. 2. Classification and diagnosis of diabetes: Standards of medical care in diabetes-2018. Diabetes Care 2018, 41, S13-S27. [CrossRef] [PubMed]

27. Cho, Y.S.; Lee, J.Y.; Park, K.S.; Nho, C.W. Genetics of type 2 diabetes in east asian populations. Curr. Diabetes Rep. 2012, 12, 686-696. [CrossRef] [PubMed]

28. Saxena, R.; Saleheen, D.; Been, L.F.; Garavito, M.L.; Braun, T.; Bjonnes, A.; Young, R.; Ho, W.K.; Rasheed, A.; Frossard, P.; et al. Genome-wide association study identifies a novel locus contributing to type 2 diabetes susceptibility in sikhs of punjabi origin from india. Diabetes 2013, 62, 1746-1755. [CrossRef] [PubMed]

29. Li, H.; Gan, W.; Lu, L.; Dong, X.; Han, X.; Hu, C.; Yang, Z.; Sun, L.; Bao, W.; Li, P.; et al. A genome-wide association study identifies grk5 and rasgrp1 as type 2 diabetes loci in chinese hans. Diabetes 2013, 62, $291-298$. [CrossRef] [PubMed]

30. Morris, A.P.; Voight, B.F.; Teslovich, T.M.; Ferreira, T.; Segre, A.V.; Steinthorsdottir, V.; Strawbridge, R.J.; Khan, H.; Grallert, H.; Mahajan, A.; et al. Large-scale association analysis provides insights into the genetic architecture and pathophysiology of type 2 diabetes. Nat. Genet. 2012, 44, 981-990.

31. Saxena, R.; Elbers, C.C.; Guo, Y.; Peter, I.; Gaunt, T.R.; Mega, J.L.; Lanktree, M.B.; Tare, A.; Castillo, B.A.; Li, Y.R.; et al. Large-scale gene-centric meta-analysis across 39 studies identifies type 2 diabetes loci. Am. J. Hum. Genet. 2012, 90, 410-425. [CrossRef] 
32. Cho, Y.S.; Chen, C.H.; Hu, C.; Long, J.; Ong, R.T.; Sim, X.; Takeuchi, F.; Wu, Y.; Go, M.J.; Yamauchi, T.; et al. Meta-analysis of genome-wide association studies identifies eight new loci for type 2 diabetes in east asians. Nat. Genet. 2011, 44, 67-72. [CrossRef]

33. Matsuba, R.; Sakai, K.; Imamura, M.; Tanaka, Y.; Iwata, M.; Hirose, H.; Kaku, K.; Maegawa, H.; Watada, H.; Tobe, K.; et al. Replication study in a japanese population to evaluate the association between 10 snp loci, identified in european genome-wide association studies, and type 2 diabetes. PLOS ONE 2015, 10, e0126363. [CrossRef]

34. Pulizzi, N.; Lyssenko, V.; Jonsson, A.; Osmond, C.; Laakso, M.; Kajantie, E.; Barker, D.J.; Groop, L.C.; Eriksson, J.G. Interaction between prenatal growth and high-risk genotypes in the development of type 2 diabetes. Diabetologia 2009, 52, 825-829. [CrossRef]

35. Zhao, J.; Li, M.; Bradfield, J.P.; Wang, K.; Zhang, H.; Sleiman, P.; Kim, C.E.; Annaiah, K.; Glaberson, W.; Glessner, J.T.; et al. Examination of type 2 diabetes loci implicates cdkal1 as a birth weight gene. Diabetes 2009, 58, 2414-2418. [CrossRef] [PubMed]

36. Kwak, S.H.; Park, K.S. Genetics of type 2 diabetes and potential clinical implications. Arch. Pharm. Res. 2013, 36, 167-177. [CrossRef] [PubMed]

37. Barker, D.J.P. In utero programming of chronic disease. Biochem. Soc. Med. Res. Soc. 1998, 95, 14.

38. Ingelsson, E.; Langenberg, C.; Hivert, M.F.; Prokopenko, I.; Lyssenko, V.; Dupuis, J.; Magi, R.; Sharp, S.; Jackson, A.U.; Assimes, T.L.; et al. Detailed physiologic characterization reveals diverse mechanisms for novel genetic loci regulating glucose and insulin metabolism in humans. Diabetes 2010, 59, 1266-1275. [CrossRef] [PubMed]

Publisher's Note: MDPI stays neutral with regard to jurisdictional claims in published maps and institutional affiliations. 